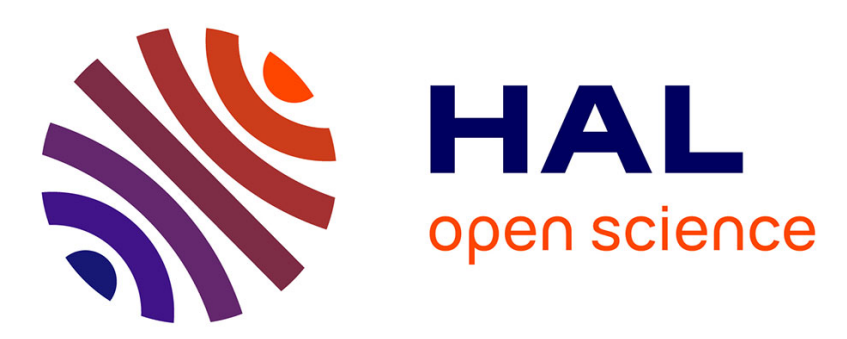

\title{
Linking phloem function to structure: Analysis with a coupled xylem-phloem transport model
}

\author{
T. Hölttä, M. Mencuccini, E. Nikinmaa
}

\section{To cite this version:}

T. Hölttä, M. Mencuccini, E. Nikinmaa. Linking phloem function to structure: Analysis with a coupled xylem-phloem transport model. Journal of Theoretical Biology, 2009, 259 (2), pp.325. 10.1016/j.jtbi.2009.03.039 . hal-00554601

\section{HAL Id: hal-00554601 \\ https://hal.science/hal-00554601}

Submitted on 11 Jan 2011

HAL is a multi-disciplinary open access archive for the deposit and dissemination of scientific research documents, whether they are published or not. The documents may come from teaching and research institutions in France or abroad, or from public or private research centers.
L'archive ouverte pluridisciplinaire HAL, est destinée au dépôt et à la diffusion de documents scientifiques de niveau recherche, publiés ou non, émanant des établissements d'enseignement et de recherche français ou étrangers, des laboratoires publics ou privés. 


\section{Author's Accepted Manuscript}

Linking phloem function to structure: Analysis with a coupled xylem-phloem transport model

T. Hölttä, M. Mencuccini, E. Nikinmaa

PII: S0022-5193(09)00144-1

DOI: doi:10.1016/j.jtbi.2009.03.039

Reference: YJTBI 5520

To appear in: $\quad$ Journal of Theoretical Biology

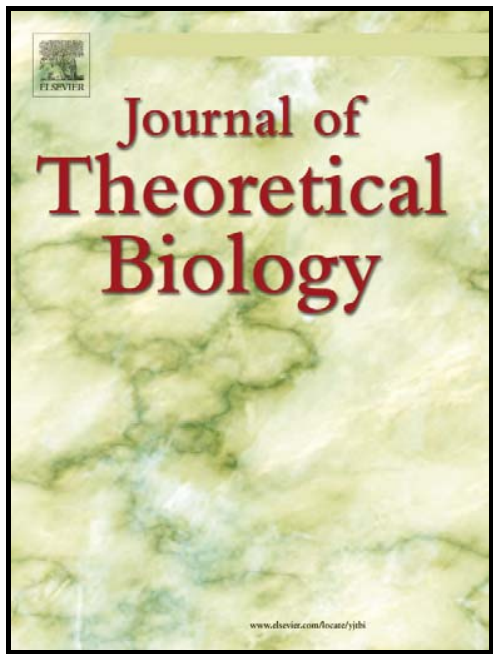

www.elsevier.com/locate/yjtb

Received date: 9 December 2008

Revised date: $\quad 26$ February 2009

Accepted date: $\quad 30$ March 2009

Cite this article as: T. Hölttä, M. Mencuccini and E. Nikinmaa, Linking phloem function to structure: Analysis with a coupled xylem-phloem transport model, Journal of Theoretical Biology (2009), doi:10.1016/j.jtbi.2009.03.039

This is a PDF file of an unedited manuscript that has been accepted for publication. As a service to our customers we are providing this early version of the manuscript. The manuscript will undergo copyediting, typesetting, and review of the resulting galley proof before it is published in its final citable form. Please note that during the production process errors may be discovered which could affect the content, and all legal disclaimers that apply to the journal pertain. 


\section{Linking phloem function to structure: Analysis with a coupled xylem-phloem transport model}

\section{T. Hölttä ${ }^{\mathrm{a}, \mathrm{b}, \mathrm{c}}$, M. Mencuccini ${ }^{\mathrm{a}}$ and E. Nikinmaa}

${ }^{\mathrm{a}}$ School of GeoSciences, University of Edinburgh, Crew Building, West Mains Road, EH9 3JN Edinburgh, UK

${ }^{b}$ Department of Forest Ecology, P.O. Box 24, FIN-00014 University of Helsinki, Finland.

${ }^{\mathbf{c}}$ To whom correspondence should be addressed. Email : teemu.holtta@helsinki.fi

Running title: Linking phloem function to structure

\section{Abstract}


We carried out a theoretical analysis of phloem transport based on Münch hypothesis by developing a coupled xylem-phloem transport model. Results showed that the maximum sugar transport rate of the phloem was limited by solution viscosity and that transport requirements were strongly affected by prevailing xylem water potential. The minimum number of xylem and phloem conduits required to sustain transpiration and assimilation, respectively, were calculated. At its maximum sugar transport rate, the phloem functioned with a high turgor pressure difference between the sugar sources and sinks but the turgor pressure difference was reduced if additional parallel conduits were added or solute relays were introduced. Solute relays were shown to decrease the number of parallel sieve tubes needed for phloem transport, leading to a more uniform turgor pressure and allowing faster information transmission within the phloem. Because xylem water potential affected both xylem and phloem transport, the conductance of the two systems was found to be coupled such that large structural investments in the xylem reduced the need for investment in the phloem and vice versa.

Keywords: Phloem translocation, sieve tube, Münch hypothesis, solute relays, xylem flow, water potential, viscosity, conduit tapering

\section{Introduction}


It is generally acknowledged that the hypothesis for osmotically driven phloem transport as put forth by Münch in the 1930s can explain phloem sugar translocation (e.g., Minchin and Lacointe, 2004; Taiz and Zeiger, 1998). According to the hypothesis, the phloem consists of continuous pathways sieve tubes, whereby sugar loading to the source end of the transport structure will osmotically draw in water from surrounding tissue and create a hydrostatic pressure gradient to drive the sap to the sink regions of the tube where sugars are unloaded. The behaviour of sugar transport in single continuous sieve tubes within constant water potential surroundings is very well understood due to numerous modelling studies (e.g. Christy and Ferrier, 1973; Philips and Dungan, 1993; Smith et al., 1980; Thompson and Holbrook, 2003a), while the functioning of a collection of sieve tubes at the whole plant level or the effects of hydraulic coupling to the xylem have received less attention. Theoretically, hydraulic coupling to the xylem is significant as phloem is close to water potential equilibrium with the surrounding apoplast (Thompson and Holbrook, 2003b) and also with the surrounding xylem (Daudet et al., 2002; Hölttä et al., 2006a). Any changes in xylem water potential will therefore be transmitted to the phloem. Since transpiration from the leaves creates a water potential gradient that drives xylem water transport, net translocation of sugars and other solutes in the phloem must work against this overall gradient. A turgor pressure gradient must be created in the opposite direction by an osmotic pressure gradient to counteract and exceed the water potential gradient created by transpiration and to overcome the viscous pressure losses due to phloem transport itself. For instance, experimental evidence shows decreased phloem exudation rate in connection with more negative xylem water potentials (Hall and Milburn, 1973; Peel and Weatherly, 1962). 
It has also been argued that maximisation of mass translocation of sugars is not the only criterion on which phloem transport is based (Thompson 2006). As plants are decentralised organisms, efficient flow regulation through information transmission between sugar sources and sinks becomes important too. Flow regulation is predicted to become difficult especially in tall trees. With the observed flow velocities, the transit time of individual molecules will be of the order of days if not weeks in continuous sieve tubes running all the way from the leaves to the roots in tall trees (Thompson and Holbrook, 2003a). To overcome the problem of slow transit velocities and information transmission in long continuous tubes, a solute relay mechanism has been suggested. According to the formulation by Lang (1979), the phloem could consist of various sieve tubes connected in series. Translocation would occur according to the Münch hypothesis within a single sieve tube while solutes would be metabolically transferred from one sieve tube to the next. However, the presence of relays remains hypothetical at the moment as there has been no substantial experimental evidence in favour or against the existence of solute relays, although continuous leakage and reloading of solutes has been observed along the phloem translocation pathway (Minchin and Thorpe, 1987; McQueen et al., 2005; Thorpe and Minchin, 1996). Nevertheless, a theoretical treatment of the subject of solute relays is still important (Minchin 2007).

To study the possible range of phloem dimensions, pressures and concentrations we developed a whole-plant steady-state phloem translocation model that is linked to a xylem transport model. From the whole plant point of view, the capacity to distribute the assimilated carbohydrates to other parts of tree is as important as the transport of 
water and nutrients from the soil to leaves. The transport capacity of the phloem depends on the dimensions of the conducting tissues and the feasible driving pressure gradients within a tree. While the structural scaling of xylem has received a great deal of attention lately (e.g., West et al., 1999) hardly any consideration has been given to phloem morphology. As the carbohydrate transport in most plants takes place in the form of sugars forming viscous solutions at high concentrations, this poses a real problem for transport (Hölttä et al., 2006a; Lang, 1978). In a way, this task of constraining solution viscosity within physiological limits to allow transport of concentrated sugar concentration, could even be compared to the task of constraining xylem tensions to avoid xylem cavitation. Here, we demonstrate that there is an upper limit to the phloem sugar transport rate which is dependent not only on the photosynthesis rate and on sieve tube diameter and number, but also on the xylem water potential. This upper limit is ultimately set by sap viscosity which is an exponentially rising function of sugar concentration.

We also demonstrate how the transport problem could be alleviated, yet not entirely avoided, by a contribution of other osmolytes, such as potassium, that do not increase viscosity even in high concentrations. Potassium would be the most likely candidate for such an osmolyte as it has been measured in the phloem at quite high concentrations (Lang, 1983; Thompson and Zwieniecki, 2003). We calculate the minimum number of observed dimensions of phloem sieve tubes required to transport a given amount of sugars in steady state according to the Münch pressure flow hypothesis and show how changes in the number of tubes affected the turgor pressure gradient and information transmission. In addition, the effect of solute relays on phloem functioning is demonstrated. 


\section{Materials and Methods}

\section{Theoretical considerations on the number of xylem and phloem transport elements needed to sustain transpiration and photosynthesis}

A steady state situation whereby xylem water transport equals the transpiration rate and phloem sugar transport equals the time-averaged photosynthesis rate was considered. Additionally, sugar loading and unloading rates must be equal to the photosynthesis rate in steady state. The phloem will be close to water potential equilibrium with the xylem (Daudet et al., 2002; Hölttä et al., 2006a), differing in only by the amount needed to exchange water radially with the xylem.

The total axial conductance $\left(k_{x}^{a}\right)\left[\mathrm{m}^{3} \mathrm{~s}^{-1} \mathrm{~Pa}^{-1}\right]$ needed for the xylem to supply the transpired water can be calculated as

$$
k_{x}^{a}=\frac{E}{\Delta P_{x}}
$$

where $E$ and $\Delta P_{x}$ are transpiration rate $\left[\mathrm{m}^{3} \mathrm{~s}^{-1}\right]$ and xylem water pressure difference between soil and leaf xylem $[\mathrm{Pa}]$, respectively. Xylem pressure is here equal to the xylem water potential, as the osmotic concentration in the xylem is assumed to be negligible. 
The total axial phloem conductance $\left(k_{p}^{a}\right)$ needed to transport a certain amount of sugars can be estimated as

$$
k_{p}^{a}(c)=\frac{J_{p}}{\Delta P_{p}}
$$

where $J_{p}$, and $\Delta P_{p}$ are phloem sap flow rate $\left[\mathrm{m}^{3} \mathrm{~s}^{-1}\right]$ and the turgor pressure difference between the loading and unloading end of the phloem [Pa]. As hydraulic conductance is dependent on viscosity, which is dependent on sugar concentration $c$, phloem hydraulic conductance will be dependent on sugar concentration. Phloem sap is assumed to be pure sucrose solution, except in the simulation where the effects of osmolytes, such as potassium, are explicitly considered. In steady state conditions, the phloem sap flow rate is determined by the time-averaged photosynthesis rate $(A[\mathrm{~mol}$ $\left.\left.\mathrm{s}^{-1}\right]\right)$ and phloem sap concentration $\left[\mathrm{mol} \mathrm{m}^{-3}\right]$

$$
J_{P}=\frac{A}{c}
$$

Phloem sap flow rate and concentration will be dependent on the vertical position. The xylem and phloem were assumed to be in equilibrium, i.e. $P_{x}=P_{p}-c R T$ (water potential losses due to radial transport are assumed to be negligible). Combining this with equations (2) and (3) yields

$$
k_{p}^{a}=\frac{A}{c\left(\Delta c R T-\Delta P_{x}\right)}
$$


Where $\Delta P_{\mathrm{x}}$ is the difference in xylem water potential between the sink (soil or roots), and source (leaves) ends of the tree, $\Delta c$ is the difference in sap concentration between the sugar source and sink ends of the phloem, $R$ is the universal gas constant, and $T$ is temperature. Note that it is possible for the term $\left(\Delta \mathrm{cRT}+\Delta P_{\mathrm{x}}\right)$ to obtain negative values, which would indicate that phloem sap flows in the upwards direction, but this situation is not relevant to our analysis. When photosynthesis rates increase while phloem conductance remains constant, a higher turgor pressure differential must be created within opposing ends of a sieve tube and/or phloem sap must become more concentrated to ensure that all the sugars can be transported. As the conductance needed depends on sap concentration, sap flux and viscosity which interact with each other and vary considerably along the phloem pathway, a numerical steady-state phloem translocation model is needed to calculate the relationship between minimum phloem conductance, photosynthesis rate and xylem water potential.

\section{Description of the steady state phloem translocation model}

The model tree was divided vertically into $\mathrm{N}$ elements for the numerical solution and xylem water pressure, phloem water pressure and concentration were found at each height. Diameter and number of conduits, plant height, photosynthesis rate, transpiration rate, and xylem water potential at leaf and soil were given as inputs to the model. Typical transpiration, photosynthesis rates and xylem water potentials 
were obtained from the literature. Xylem and phloem axial conduit hydraulic conductance of each vertical element $\left(k_{i}^{a}\right)$ were calculated from Poiseuille's law to be

$$
\begin{aligned}
& k_{x, i}^{a}=\frac{8 \pi a_{x, i}{ }^{4}}{l_{i} \eta_{x, i}} n_{x, i} K_{x, p} \\
& k_{p, i}^{a}=\frac{8 \pi a_{p, i}{ }^{4}}{l_{i} \eta_{p, i}\left(c_{i}\right)} n_{p, i} K_{p, p}
\end{aligned}
$$

where the subscript $x$ and $p$ refer to xylem and phloem respectively and $l_{i}, a_{i}, n_{i}, \eta_{x}$ $\eta_{p}(c), K_{x, p}$ and $K_{p, p}$ are element length, tube radius, number of parallel tubes, xylem and phloem viscosity [Pa s] and dimensionless factors accounting for the effect of the inter-conduit pits and sieve pore plates on the axial hydraulic conductance of the xylem and phloem, respectively.

The xylem water pressure $\left(P_{x, i}\right)$ at each element was calculated to be the water pressure of the element underneath it (for the bottommost element, i.e. the element at the sugar sink, this was the soil water potential) minus the effects of gravity and pressure losses caused by xylem sap flux, which was set equal to transpiration rate

$$
P_{x, i}=P_{x, i-1}-\rho g l_{i}-\frac{E}{k_{x, i}^{a}}
$$

where $\rho, g$ and $l_{i}$ are water density, the gravitational constant and element length, respectively. In reality, xylem water flux does not precisely equal the transpiration 
rate because a fraction of the water flow in the xylem is drawn into the phloem. However, the water entering the phloem is a minor proportion of the xylem water flux when transpiration is large compared to phloem sap flux, which was the case in all the situations presented later in this study. This effect was therefore neglected for simplicity. For each vertical phloem element, equations of radial water exchange with the xylem, axial sap flow, water conservation, and sugar conservation were written

$$
\begin{aligned}
& J_{i}^{r}=\left(P_{x, i}-P_{p, i}+c_{i} R T\right) k^{r} A_{r} \\
& J_{p, i}^{a}=\left(P_{p, i}-P_{p, i-1}+\rho g l_{i}\right) k_{p, i}^{a} c_{i} \\
& J_{p, i}^{a}=J_{i}^{r}+J_{p, i-1}^{a} \\
& J_{s, i}=J_{s, i-1}+S_{i}
\end{aligned}
$$

Where $J_{i}^{r}, J_{p, i}^{a}, J_{s, i}, P_{x, i}, P_{P, i}, c_{i}, k^{r}, k_{p, i}^{a}, A_{r}$, and $S_{i}$, are radial water exchange with the xylem, axial phloem sap flux, axial solute flux, xylem water pressure, phloem turgor pressure, phloem sugar concentration, radial hydraulic conductance, axial hydraulic conductance of phloem, cross-sectional area of radial water exchange, sugar loading/unloading rate $(\mathrm{j}=1$ for unloading and $\mathrm{j}=\mathrm{N}$ for loading, respectively. Note that $P_{x, i}$ was calculated from the xylem fluxes as explained earlier. 
Sugar loading rate to the uppermost phloem element was equal to the photosynthesis rate as we assumed that over any extended period of time sugars cannot accumulate excessively into leaves. Sugar unloading rate was also equal to the loading rate, but it was necessary to formalize unloading to be a function of sugar concentration in order to have a closed form solution (see Goeschl et al., 1976; Thompson and Holbrook, 2003a). Sugar unloading rate at the bottommost element $(j=1)$ was given the following form

$S_{1}=\left(c_{1}+\frac{P_{x, 1}-P_{a}}{R T}\right) A_{1}$

where $A_{1}$ is a constant and the second term inside the parentheses is a "target osmotic concentration" in which $P_{a}$ is a "target turgor pressure". $A_{1}$ represents the "vigour" of unloading in relation to a "target osmotic concentration". $A_{1}$ was chosen to be very high, which practically led to the sugar concentration at the unloading zone to be equal to $-\left(P_{x, 1}-P_{a}\right) / R T$. This form of the unloading function also ensured that negative values for phloem turgor pressure, which would cause plasmolysis, were avoided in all situations.

The viscosity of the phloem sap $\left(\eta_{p, i}\right)$ was made a function of the sucrose concentration of the phloem sap at each element. Phloem sap viscosity was calculated at each vertical element from the equation (Morison, 2002)

$\eta_{p, i}=\eta_{0} \exp \left(\frac{4.68 * 0.956 \phi}{1-0.956 \phi}\right)$ 
where $\eta_{0}$ is viscosity of pure water and $\phi$ is the volume fraction of sucrose in the phloem sap (calculated from the sugar concentration). This equation describes the sucrose dependency of viscosity accurately up to sucrose concentrations of 7.5 MPa. In solving the equations for phloem translocation we followed the method described by Goeschl et al. (1976) with the addition of vertically varying xylem water potential and concentration dependent phloem sap viscosity.

The water pressure at each vertical element in the xylem was calculated with Eq. (6). An arbitrary initial value was first given to the sugar concentration at the source end of the phloem. Equations (7)-(12) were solved first for the topmost phloem element (i.e., the element at the source or leaves) and then for the other elements following a procedure described in Appendix A. Then the total water exchange over all the elements between the xylem and phloem was calculated from eq. (7). At steady state, the sum of radial water exchange over all the elements must be zero. If not zero, then the sugar concentration at the topmost phloem element was given a new value and the whole procedure for the phloem was repeated until the sum of water exchange over all the elements was zero. If a steady-state solution was not found, then the phloem hydraulic conductance was deemed not to be sufficient, i.e. there were not enough phloem sieve tubes.

The equations for phloem transport lead to a closed form solution to the steady state phloem translocation problem when viscosity is constant, i.e., there is only one concentration, turgor pressure, axial sap flow, radial water exchange vertical profile and provided that phloem unloading at the bottommost element is concentration dependent (see Goeschl et al., 1976). However, when viscosity is made concentration 
dependent, there will be two solutions to the equations (of which only one is a stable one), until photosynthesis increases so much in proportion to phloem conductance that no solution can any longer be found. Hence, there is a point where two solutions converge into one. This point therefore identifies the maximum sugar transport rate in the phloem, and hence the maximum photosynthesis rate, for a given set of parameters (e.g., number of available sieve tubes).

\section{Modelling solute relays}

To model solute relays, the phloem was assumed to consist of several sieve tubes connected in series on top of each other. The separate sieve tubes were assumed to be hydraulically isolated from each other. The same equations (Eqs. 7 to 12) that described the phloem transport for a continuous sieve tube were in this case solved separately for each sieve tube. The loading rate to one sieve tube was made equal to the unloading rate from the sieve tube above it.

\section{The effect of additional solutes on phloem transport}

Additional simulations were carried out, by including another solute, which did not contribute to viscosity increase, but still raised the phloem osmotic concentration. In this case the additional solute, e.g. a potassium ion, was loaded to the phloem at the same sites as sugar loading and was unloaded from the sieve tubes together with the sugar. We will simply refer to the additional solute as potassium in the future. 
Continuous transport of potassium in the phloem as is proposed here requires that potassium is recycled back to the sugar sources through the xylem and this is indeed what has been found to occur in reality (Flowers and Yeo, 1992; Lang, 1983; Zwieniecki et al., 2001). It is also necessary for the potassium to be actively loaded and unloaded to and from the phloem against a concentration gradient. The circulation of potassium also influences the xylem water potential through its osmotic effect, but the effect is much smaller compared to the phloem, as potassium concentrations are much more diluted in the larger xylem sap pool and so this is not taken into account in the simulations.

Turgor pressure differentials over the tube, transit and wave propagation times

The only constraint set on phloem translocation with the above approach was that phloem must be able to translocate all sugars from one end of the plant to the other in steady state. However, there might also be other constrictions to the functioning of the phloem, as Thompson (2006) pointed out. It may be that the turgor pressure differential between the opposite ends of the phloem translocation pathway is limited, so all cells maintain a relatively constant turgor pressure for physiological functioning (Thompson and Holbrook, 2004).

Information is transmitted by individual molecules moving at the solution bulk flow velocity and therefore the transit time of the solution $\left(\tau_{s}\right)$ would be the parameter describing this kind of information transmission rate. However, information on local changes in water pressure and sugar concentration may be transmitted faster than 
individual molecules in the form of pressure and concentration waves, provided that the ratio of solution osmotic concentration to turgor pressure differential is large (Thompson and Holbrook, 2004). Thompson and Holbrook (2003b) described this dimensionless ratio with the symbol $F$

$$
F=\frac{\theta}{\Delta P}
$$

where the characteristic sugar concentration $(\theta)$ is taken to be the sugar concentration at the unloading end of the sieve tube and $\Delta \mathrm{P}$ is the pressure difference between source and sink ends of the sieve tube. Also Philips and Dungan (1993) used a similar approach. Thompson and Holbrook (2004) estimated the transit time of the pressure and concentration waves $\left(\tau_{p}\right)$ from the transit time of individual molecules $\left(\tau_{s}\right)$ to be

$$
\tau_{p}=\frac{\tau_{s}}{2 F}
$$

provided that $F$ is larger than unity. Thompson (2005) further concluded that sieve tube elasticity is insignificant in evaluating the speed of the pressure and concentration waves. The estimate for transit time of the pressure and concentration waves can also be expressed in another form, which shows the effect of individual parameters more clearly (Thompson, 2006)

$$
\tau_{p}=\frac{\mu l^{2}}{2 R T \theta k_{s}}
$$


where $k_{s}$ is the specific conductivity (hydraulic conductivity per unit functional crosssectional area) of the tube. Also Ferrier (1976) gives a very similar estimate for the concentration wave propagation velocity in the phloem. We used Equations (13) to (15) to give qualitative estimates of the transmission of pressure and concentration waves in the phloem. However, it must be remembered that although pressure and concentration waves have a sound theoretical basis they remain a poorly established phenomena experimentally and their formulation is only an approximation, as assumptions of spatially constant osmotic concentration and xylem water potential were made in its derivation

\section{Model runs and parameters}

The number of xylem and phloem tubes of constant diameter that would give the required transport rate at a given xylem water potential was calculated by the model. Initially, the number of phloem tubes was set high, and the number of tubes was progressively reduced until phloem could not transport all the photosynthesized sugars anymore. The values for transpiration, photosynthesis rates and xylem water potential were chosen to represent a typical $10 \mathrm{~m}$ tall tree (Table 1). The diurnal maximum value used for transpiration was $0.9 \mathrm{mmol} \mathrm{m}^{-2} \mathrm{~s}^{-1}$, which equals $0.9 \mathrm{~g} \mathrm{~s}^{-1}$ for a tree with $50 \mathrm{~m}^{2}$ leaf area. The diurnal maximum value used for photosynthesis was $7.0 \mu \mathrm{mol} \mathrm{m} \mathrm{m}^{-2} \mathrm{~s}^{-1}$. This is equal to a sucrose loading rate of $30.0 \mu \mathrm{mol} \mathrm{s}{ }^{-1}$ for a tree with $50 \mathrm{~m}^{2}$ of leaf area. In reality however, the phloem is likely not to operate in steady state since transpiration and photosynthesis vary diurnally. There is evidence that the phloem solution flux can remain more or less constant diurnally (Windt et al., 2006) 
as sugars from photosynthesis are not necessarily instantly loaded to the sieve tubes and are stored instead in the leaves. Therefore the values for the transpiration and photosynthesis rates required to calculate the amount of phloem tubes needed were chosen as diurnal maximal values divided by two and are referred to as timeaveraged. A value of -2.0 MPa was used for the minimum xylem water potential and soil water potential was set at $0 \mathrm{MPa}$. The value for radial conductance between the xylem and phloem was set at $2 * 10^{-13} \mathrm{~m} \mathrm{~Pa}^{-1} \mathrm{~s}^{-1}$ (e.g., Zwieniecki et al., 2001) and the area of radial water exchange between xylem and phloem is set to be the sum of the surface areas of the phloem sieve tubes. The value of the radial hydraulic conductance and surface-area through which radial water exchange can occur is determined by the hydraulic properties of tissue linking phloem to xylem, i.e. the parenchyma, cambium or ray cells (Van Bel, 1990). For the numerical solution, the model tree was divided into 40 vertical elements, with sugar loading occurring at the top $0.25 \mathrm{~m}$ (top element) of the phloem and sugar unloading occurring at the bottom $0.25 \mathrm{~m}$ (bottom element) of the phloem. Unless otherwise noted, the parameter $\mathrm{P}_{\mathrm{a}}$ in Eq. (11) is set at $1 \mathrm{MPa}$, which in practise means that the sieve tube turgor pressure will be very close to 1 $\mathrm{MPa}$ and osmotic pressure very close to $-1 \mathrm{MPa}$ at the sink. The factors $K_{x, p}$ and $K_{p, p}$ accounting for the effects of inter-conduit pits and sieve pore plates on the axial conductivities of the xylem and phloem were set to be 0.5 , i.e., both accounted for half of the total resistance to sap flow in the xylem and phloem. While the resistance of the xylem inter-conduit pits to water flow is relatively well known (e.g., Choat et al., 2006; Lancashire and Ennos, 2002; Wheeler et al., 2005), the resistance of the phloem sieve plates remains largely unknown (Thompson and Holbrook, 2003a). 


\section{Results}

To demonstrate the character of the steady state solutions for phloem translocation, the sums of the radial water fluxes between xylem and phloem over the length of the stem as a function of the sugar concentration at the source end of the phloem sieve tubes are shown in Figure 1A) for four different cases of number of phloem tubes. A value of zero corresponds to the steady state situation, while positive values indicate net water flux to the phloem and negative values flux from the phloem. For comparison, a net radial water flux of $0.9 * 10^{-6} \mathrm{~m}^{3} \mathrm{~s}^{-1}$ corresponds to the axial xylem water flux. For a large number of pipes there were two solutions, i.e., sum of radial fluxes is zero for two different sugar concentrations in the loading zone. As the number of pipes decreased, the solutions moved closer to each other, until they converged into one and with a further decrease in the number of pipes, no solution could be found any longer which means that not all the photosynthesized sugars could be transported from the leaves. The significance of the two solutions can be understood by considering that a fixed amount of sugars can be transported in steady state either with a smaller sugar concentration (which leads to lower viscosity) coupled to a large turgor pressure gradient, or with a larger sugar concentration and higher viscosity, but lower turgor pressure gradient (cf., Eqn. 4). However, only the solution with the smaller sugar concentration and turgor pressure is a stable one, i.e. a small deviation from this state will make the system return back to it, whereas the solution with the larger sugar concentration and turgor pressure is an unstable one and will not be reached in practice. Clearly, there was a minimum number of sieve tubes needed for phloem transport, which was dependent on the environmental conditions 
(transpiration and photosynthesis rates and soil water potential) and sieve tube and xylem conduit structure (sieve tube and xylem conduit diameter and the resistance of sieve plates and bordered pits). The minimum number of pipes corresponded to the case where the two solutions converged into one. Similarly, there was an upper limit for the amount of sugars which could be transported in the phloem if the number of tubes was fixed (due to the viscosity effect, not shown). Therefore, if transpiration or photosynthesis is increased or the number of xylem or phloem tubes decreased, there would be no steady state solution and the phloem would not be able to maintain the required sugar transport rate. Figure 1B) shows the vertical distribution of turgor and osmotic pressure for the case of the minimum number of sieve tubes and for the case where there is twice the number of minimum number of tubes. Note that the later has two solutions as explained above. For the case with the minimum number of phloem tubes, the ratio of the number of xylem to phloem tubes needed for transport was 22 , given that xylem conduits and phloem sieve tubes had equal diameters. In absolute numbers this is 2200000 tubes for the xylem and 100000 tubes for phloem, each tube being $10 \mu \mathrm{m}$ in radius. If xylem conduits were larger in diameter than phloem sieve tubes, as would be the case at least for typical angiosperm vessels, then less xylem conduits would be needed in relation to phloem sieve tubes, the ratio being decreased by the ratio of the xylem conduit to phloem sieve tube radius elevated to the fourth power. For this, the transit time of individual phloem molecules was approximately 7 hours over a length of $10 \mathrm{~m}$, while parameter $F$ (see eq. 13) fells below unity, and therefore the propagation of pressure and concentration waves was not any faster than the bulk phloem solution velocity. The effect of radial resistance was small. The factor of radial conductance times the contact area between xylem and phloem was so high that the phloem was close to thermodynamic equilibrium with the xylem. A 
decrease in the radial conductance lead to larger pressure losses in association with radial exchange of water and more phloem pipes were needed (not shown). The number of phloem tubes required for mass translocation increased in the same proportion as the photosynthesis rate was increased (i.e. if photosynthesis rate doubled then amount of conduits needed doubled also, not shown).

\section{Effect of xylem water potential on phloem transport}

The number of phloem tubes needed to translocate photosynthesized sugars (or the maximum amount of sugars that could be transported for a given phloem structure) was also strongly dependent on the xylem water potential. When the xylem water potential decreased, there was an increase in the minimum number of phloem tubes needed for sugar translocation (Fig. 2). Note that Fig. 2 shows the daily minimum xylem water potential. The water potential used to calculate phloem translocation was only half as much as for the xylem as phloem transport was thought to occur evenly throughout day and night, i.e. a daily minimum water potential was used for the calculation of xylem transport, but a daily average water potential was used for the calculation of phloem transport. However, when water potential decreased for a given transpiration rate, fewer xylem conduits were needed to supply water to the leaves, because the water potential gradient driving the xylem was larger (Fig. 2). Hence, the total number of tubes simultaneously needed for xylem and phloem transport was minimised at an intermediate value of xylem water potentials. The effects of decreasing xylem water potential can qualitatively be seen from equations (1) and (4) as an increase in the driving force for the xylem and a decrease in the driving force for 
the phloem. The transit time of individual molecules increased at the same rate as the number of phloem tubes (not shown), while parameter $F$ remained below unity. The number of phloem tubes required for the transport of photosynthates cannot be explicitly expressed in terms of water use efficiency, since it is not the transpiration rate per se which determines the requirements for phloem construction, but the xylem water potential.

\section{Solute relays}

When solute relays were included in the model, as suggested by Lang (1979), the profiles of phloem transport changed considerably. Figure 3 illustrates turgor pressure, osmotic pressure and water potential gradients for the phloem when either one (3A) or four relays $(3 \mathrm{~B})$ were added. Other parameters, including the transpiration and photosynthesis rate were the same as in the previous case without relays. Axial and radial phloem flows are shown in fig. 3C) for the case of two relays. The distance between the relays is evenly spaced throughout the tree. Water was pushed out of the phloem to the xylem at the unloading site of each relay and entered back to the

phloem from the xylem at the loading site of the relay. Turgor pressure, sugar concentration and axial and radial water fluxes remained similar in different relays throughout the phloem. Within each relay, the local turgor gradient did not change much compared with the case of a continuous tube, as the same amount of sugars was still transported with similar sugar concentrations. However, with the relays, a more uniform turgor was achieved throughout the phloem as the turgor pressure difference between the source and sink dropped considerably. The transit time of individual 
molecules (not shown) decreased when relays were added (although less than linearly as a function of number of relays). $F$ increased slightly and therefore wave propagation time decreased faster than transit time as a function of number of relays (Eqn. 14).

When relays were included, the phloem was capable of transporting sugars with considerably fewer parallel tubes, compared with case of the continuous sieve tube. Figure 3D shows the number of tubes required to transport a given amount of sugars as a function of number of relays, relative to the number of tubes required when no relays were present. The number of required parallel tubes and also the transit time of individual molecules (not shown), were approximately inversely proportional to number of tubes in series, i.e., number of relays minus one. $F$ remained approximately constant and pressure and concentration wave transit time behaved similarly to mass translocation transit time, i.e., they were inversely related to the number of relays. However, with relays, radial resistance became more important as there was more water exchange with the surrounding tissue than in the continuous sieve tube case. The amount of parallel sieve tubes required for mass translocation with relays increases in direct proportion to photosynthesis like as in the case of no relays.

\section{Turgor uniformity, transit time and information transmission}

For the simulations where the minimum number of required phloem tubes was calculated, the phloem was always functioning at a very high turgor pressure 
difference between the loading and unloading zone, as this maximized the amount of sugars that could be transported for a given phloem structure. Therefore the requirement of a more or less uniform turgor throughout the phloem was not met. The high turgor pressure difference also led to low values of $F$, i.e., low propagation velocity of pressure and concentration waves in relation to solution velocity. If the amount of sugars to be transported remains fixed, then diameter and/or number of the tubes must be increased to decrease the turgor pressure gradient. Also the terminal sink could be simultaneously kept at a higher sugar concentration, by increasing the parameter $\mathrm{P}_{\mathrm{a}}$ in Eqn. (11), leading to higher turgor pressure at the sink. We simulated how turgor pressure difference, $F$, transit time of the solution, and the rate of information transmission were affected when more parallel phloem sieve tubes were added with a fixed sugar loading rate (Fig. 4). Results are shown for different (0.1, 1 and $2 \mathrm{MPa}$ ) "target" sugar concentrations (see eq. (11)) at the sugar unloading zone. The pressure difference between the two ends of the phloem obviously decreased when more tubes were added (Fig. 4A). Parameter $F$ also increased with added tubes, roughly with an inverse proportionality to the pressure difference. However, the transit time of the solution increased (Fig. 4B). Consequently, there was essentially no effect on the transit time of the pressure and concentration waves, as both $F$ and the transit time increased in nearly the same manner (Fig. 4B). For the case of sugar concentrations of $0.1 \mathrm{MPa}$ at the sugar unloading zone, wave propagation could not be calculated as $F$ was below unity. If the sugar concentration at the sink was increased, then more tubes were needed for bulk sugar translocation. The pressure difference over the tube was not strongly affected by the increase in sugar concentration at the sink, whereas $F$ and transit time increased when sink sugar 
concentration was increased. The effect on the estimated wave propagation time was mixed and not very strong.

\section{Phloem conduit diameter and tapering}

Phloem hydraulic conductance is strongly dependent on sieve tube diameter. It follows readily from the equations that the minimum number of tubes needed is related inversely to the tube diameter raised to the fourth power, while the transit time and wave propagation time is related to the inverse of diameter squared, provided that the fraction of total resistivity determined by the sieve plate remains constant. There is sparse evidence that phloem diameters change vertically within a plant and increase in diameter in taller plants compared to shorter plants (Mencuccini et al., unpublished data). When phloem sieve tube tapering was incorporated into the phloem translocation model, the predictions for osmotic and turgor pressure gradients, mass translocation and information transmission showed greater spatial variation. As an example, we made the phloem sieve tubes taper linearly in diameter from source to sink. The simulations were carried out by keeping the diameter of the top element constant and by progressively increasing the diameters of the bottom element to achieve greater and greater vertical tapering. With greater tapering, fewer sieve tubes were needed, wave propagation time decreased, with the effect of tapering plateauing at high tapering (Fig. 5). The transit time decreased at moderate tapering and then slightly increased at very high tapering, while changes in $F$ were small. However, if the conductace of the sieve pores increased less than proportionally compared to the conductace of the sieve tube lumen, then the significance of the sieve tube tapering on 
phloem functioning was smaller. Interestingly, the parameter most affected by tube tapering (about a factor of 10) was wave propagation time.

\section{Effect of potassium on phloem transport}

The loading of potassium to the phloem at the sugar source and unloading at the sink resulted in a decrease in the minimum number of phloem tubes required for sucrose mass transport but nevertheless the viscosity limit was still present (Fig. 6). Potassium increased the driving force for transport, the turgor pressure gradient, by the same amount as was the fraction of potassium in the phloem sap. The resulting gradient in potassium concentration acted in qualitatively the same way as the gradient in sucrose concentration (not shown), which is in accordance with earlier measurement results from the literature (Vreugdenhill, 1985). The absolute levels of potassium concentration and its gradient were naturally dependent on the potassium loading rates. Potassium concentrations have been found to reach values as high as $3 / 4$ of the sucrose concentrations (Lang, 1983) which would correspond to maximum potassium loading rates of $1 * 10^{-5} \mathrm{~mol} / \mathrm{s}$ in our study. In addition, potassium can have additional important roles in phloem transport by aiding in the osmoregulation of turgor pressure under conditions of restricted solute availability (Smith and Milburn, 1980). Also, with lower sucrose concentrations, the role of potassium can be larger (Thompson and Zwieniecki, 2005).

\section{Discussion}


Xylem structural properties have been studied in depth (e.g., Tyree and Zimmermann, 2002) but far less attention has been given to phloem structural requirements. Our study demonstrates that there exist a minimum number of phloem tubes, which is required for the transport of photosynthesized sugars from the leaves. Phloem hydraulic conductance for a given structure was limited because phloem sugar concentration necessarily increased with increasing sugar loading rate, which increased flow resistance exponentially with increasing viscosity (Lang, 1978). The viscosity problem may be limited to higher sugar translocation rates by using other solutes such as potassium, but it cannot be completely avoided as sugars need to be transported from the source to the sink in any case. Potassium merely increases the turgor pressure and its gradient by drawing in water to the phloem without increasing the solution viscosity. It is well known that low xylem water potentials cause detrimental effects on plant function by inducing xylem conduit embolism and turgor reduction in living cells (e.g. Tyree, 2003; Woodruff et al., 2004). This study suggested that decreasing xylem water potentials also limits sugar transport for a given phloem structure as water is held more tightly in the xylem (see Eq. (7)) and higher sugar concentrations are needed in the phloem to draw water in osmotically from the xylem. In a dynamic scenario, short-term changes in xylem water potential could be temporarily buffered (Hölttä et al., 2006a), but in steady state, the effects of continuous differences in xylem water potential could be clearly seen on phloem translocation. Large investment in xylem conductance to maintain high xylem water potential for a given transpiration rate reduced the need for phloem conductance for a given assimilation rate. Our modelling of the combined number of xylem and phloem tubes required for simultaneous transfer of xylem water and phloem sugars suggested 
that intermediate values of water potentials may provide the best range to minimise structural investments by the plant. It is also interesting that the intermediate values of xylem water potential where the relative numbers of both xylem and phloem conduits are relatively low, corresponds to the xylem water potentials where cavitation starts to reduce hydraulic conductivity of the xylem (Tyree and Sperry, 1988). This finding may in part help to explain why plants operate within a fairly narrow range of water potentials (e.g., Mencuccini, 2003), despite very large differences in many other structural properties.

\section{Solute relays}

With solute relays, the phloem could transport sugars with fewer conduits, maintained a more uniform turgor pressure throughout the plant and decreased the transit time of individual molecules, pressure and concentration waves. However, solute relays have a metabolic cost associated with the active loading and unloading of sugars. Lang (1979) estimated, based on the 1:1 stoichiometry of moles of ATP used per mole of sucrose transported, that approximately 2 percent of sugars would be used up in each relay. Theoretically, this metabolic cost could be compared with the carbon cost of building more and wider continuous phloem sieve tubes without relays to achieve identical sugar translocation rates. The marginal return of adding more and more relays on the number of required conduits tended to decline rapidly and with more than just a few relays, the benefits became very small. In order for the relays to function effectively, the membrane separating the two sides of the relay must be impermeable or semipermeable, i.e., it must not be permeable to solutes. If solutes 
were to pass freely from one relay to the next, they would flow back along with water from the downstream relay compartment to the upstream one following the turgor pressure gradient. However, if they were separated by a semipermeable membrane, phloem sap would not simply flow to the direction of the turgor pressure gradient, it would flow according to the water potential gradient, which is nearly equal on the opposing sides of the relay. Basically all that is required of the relay mechanism presented here is that solutes cannot pass by mass flow through some points in the translocation pathway. In practice the relays presented in this study could be nothing more than, eg., the occlusion of sieve plates or a release/retrieval mechanism on the phloem translocation pathway.

The phloem has also been shown to play an important role in xylem embolism refilling and phloem girdling has been demonstrated to prevent embolism refilling (e.g. Salleo et al., 2004; Salleo et al., 2006). A theoretical study by Hölttä et al. (2006b) showed that water released by sugar unloading from the phloem may induce xylem embolism refilling in certain conditions. Relay points would be the locations where solutes and water are released from the phloem, and theoretically these would be the places where xylem embolism refilling could occur.

\section{Different phloem construction criteria}

Two different phloem construction criteria are proposed: One with more or less constant turgor pressure, i.e., high $F$ (Thompson, 2006), and one which minimizes the number of phloem tubes but operates at large turgor pressure differentials (the 
solution of the minimum number of tubes required for translocation). The first ensures that all phloem cells are in the same range of physiological conditions, but it does not per se lead to faster information propagation along the phloem, although it leads to faster information transmission in relation to the mass flux. With high $F$, information transmission in the form of pressure and concentration waves can be rapid even if the phloem sap is at rest. Adding more tubes increased phloem conductivity, reduced the turgor pressure difference along the phloem axis and raised $F$, but it did not promote faster information propagation along the phloem. Instead, it led to increased transit time of individual molecules through the phloem, thus having adverse effects on the propagation of possible hormonal signals and increasing the amount of carbon that is invested in the phloem. It can also be argued, that it would be safer for the phloem to be slightly overbuilt rather than to function near critical construction to ensure efficient operation over a wide range of physiological conditions, just as it would be safer for the xylem to be overbuilt to ensure water tranport to the leaves in case of embolism. As can be seen from Equation (15), the parameters that determine the propagation of pressure and concentration waves are the specific conductivity, which is determined by the diameter of individual tubes (and the resistance of the sieve pores), tube length, osmotic concentration and viscosity, which is coupled to osmotic concentration at least in the case where only sucrose is considered. Wider and shorter tubes (relays) will promote faster propagation of pressure and concentration waves, faster propagation of hormonal signals and decrease the turgor pressure differences along the phloem in both of the phloem construction scenarios. The actual flow velocities that have been measured in intact plants fall somewhere between 0.2 to 0.5 mm/s (0.7 - 2 m/hour) (Köckenberger, 1997; Peuke et al., 2001; Windt et al., 2006). The flow velocity predicted by our model in the base case (Fig. 1) increases moving 
from the top to the bottom of the phloem being on average $2.4 \mathrm{~m} / \mathrm{hour}$. When the number of phloem tubes was increased, the flow velocity decreased reaching physiologically more common values (compare with transit times in Fig. 4b).

There probably are significant structural constraints on how large apical sieve tubes diameters may be. For instance, cambial cell ontogeny will dictate the rate at which new sieve tubes can enlarge basally. Apical sieve tube size is also likely to be limited by the allometry of the surrounding cells to optimise sugar loading. Hence, a gradual vertical tapering of the sieve tube elements appears to be a possible solution to achieve a reduction in solution and wave propagation times. This however requires also that changes take place in the conductivities of the tube plates. This vertical tapering and developmental changes may be similar to those already documented for the xylem (e.g. Anfodillo et al., 2004; Mencuccini et al., 2007; McCulloh et al., 2003; West et al., 1999), at least partially. In the xylem, conduit tapering is predicted to reduce the adverse effects of growing transport distance on the whole xylem pathway conductance (West et al., 1999). West et al. (1999) further pointed out that the same theoretical predictions should also apply to the phloem. Yet there is little empirical available evidence at the moment on which to base such a theoretical analysis on.

\section{Tall trees}

For tall plants it is also important to account for gravity when considering the amount of phloem and xylem tissue needed for transport. The ratio of required phloem to xylem conduits would be expected to decrease as plant height increases because 
gravity aids phloem transport while xylem works against gravity. Taking a tall $100 \mathrm{~m}$ tree as an example, the driving force for xylem translocation drops by $1 \mathrm{MPa}$ in relation to a very small tree while the driving force for phloem simultaneously increases by $1 \mathrm{MPa}$. It will take a long time for individual molecules, as well as pressure and concentration waves according to Eq. (15) (Thompson, 2006), to traverse the length of a long tree as the transit of both is related to transport distance squared, if the specific conductivity of the phloem tubes is low, due to small sieve tube radii and/or high resistance of sieve plates. With a sieve tube radius of $10 \mu \mathrm{m}$, the transit time of both individual molecules and pressure and concentration waves is expected to be at least of the order of 100 hours in continuous sieve tubes, even if the turgor pressure difference over the opposing ends of the tube is reduced. The transit time of both individual molecules and pressure and concentration waves are also predicted to decrease in approximately inverse relation to the number of solute relays. However, signals on the water status of the transpiration stream will be traversed very rapidly, in the order of hours, in the xylem of even the tallest trees (e.g., Perämäki et al., 2005). As xylem and phloem are predicted to be near thermodynamic equilibrium, phloem should thus be able to sense rapidly any changes in at least transpiration, xylem conductivity and soil water potential through this rapid propagation of pressure in xylem.

\section{Limitations and advantages of the modelling approach presented}

In the phloem transport of real plants, feedbacks between sieve tube sugar concentration and loading, unloading and reloading may have an important role. For 
example strong feedbacks between sugar concentration and sugar loading at the source have been found to exist (e.g. Vaughn et al., 2002). A steady state model approach cannot explicitly incorporate these feedbacks. Instead, our steady state approach implicitly assumes that feedback effects occur in an optimal way so that phloem sugar concentration, turgor pressure and sugar transport can remain at the "optimal" value predicted by the model regardless of transient changes in, e.g., transpiration and photosynthesis rates. The capacitive sugar storage tissue is also implicitly included in the assumption that sugars are transported in steady state. The sugar stores in the leaves have to be at least so high that sugars can be fed to the phloem close to a constant diurnal rate, even though the actual photosynthesis rate varies strongly diurnally. Despite the inherent limitations of a steady state model, the value of our approach is in showing what limiting factors may constrain the maximum sugar transport capacity of the phloem and how much the requirements for this maximum capacity must be relaxed in order to achieve more rapid information transmission.

\section{Carbon costs of the phloem}

The amount of carbon required to build the phloem tubes needed to transport the photoassimilates may be considerable, especially if the turgor pressure difference along the plant axis has to be maintained uniform. The introduction of solute relays and tube tapering reduce the number of sieve tubes needed, but the functioning of the relays requires additional energy input and wider conduits probably require structural reinforcement to resist turgor pressure forces on their walls. As mentioned, there is 
also a trade-off between xylem and phloem construction. By larger investement in the xylem, trees are able to reduce phloem construction cost. This links the phloem construction to other factors influencing the long-term survival of trees. The approach presented here shows that carbon cost of building xylem and phloem can potentially be compared and analysed from a functional point of view. Additional studies on this topic are needed.

Acknowledgements: The research was funded by $T$. Hölttä's grant from Helsingin Sanomain 100-vuotissäätiö and The Academy of Finland projects nro. 12548 and 13699. 


\section{References}

Anfodillo, T., Carraro V., Carrer M., Fior, C., Rossi, S., 2006. Convergent tapering of xylem conduits in different woody species. New Phytologist, 169, 279-290 $\underline{\text { Scopus. }}$

Choat, B., Brodie, T., Cobb, A.R., Zwieniecki, M.A, Holbrook, N.M., 2006. Direct measurements of intervessel pit membrane hydraulic resistance in two angiosperm tree species. American Journal of Botany, 93, 993-1000 Scopus.

Christy, A.L., Ferrier, J.M., 1973. A mathematical treatment of Münch's pressureflow hypothesis of phloem translocation. Plant Physiol., 52, 531-538.

Daudet, F.A, Lacointe, A., Gaudillere, JP., Cruiziat P., 2002. Generalized Münch coupling between sugar and water fluxes for modelling carbon allocation as affected by water status. J. Theor. Biol. 214, 481-498 Scopus.

Ferrier, J.M., 1976. An approximate analytic equation for sugar concentration waves in Münch phloem translocation systems. Canadian Journal of Botany 54, 21302132.

Flowers, T.J., Yeo, A.R., 1992. Solute transport in plants. Blackie Academic \& Ptofessional. Chapman \& Hall. Glasgow, UK.

Goeschl, J.D., Magnuson, C.E., DeMichele, D.W., Sharpe, P.J.H., 1976.

Concentration-dependent unloading as a necessary assumption for a closed form mathematical model of osmotically driven pressure flow in phloem. Plant Physiol., 58, 556-562.

Hall, S.M., Milburn, J.A., 1973. Phloem transport in Ricinus: its dependence on the water balance of the tissues. Planta, 109, 1-10 Scopus.

Hölttä, T., Vesala, T., Sevanto, S., Perämäki M., Nikinmaa, E., 2006a. Modeling xylem and phloem water flows in trees according to cohesion theory and Münch hypothesis. Trees: Structure and Function, 20, 67-78 Scopus. 
Hölttä, T., Vesala, T., Perämäki, M., Nikinmaa, E. 2006b. Refilling of embolised conduits as a consequence of "Münch water" circulation. Functional Plant Biology, 33, 949-959 Scopus.

Köckenberger, W., Pope, J.M., Xia, Y., Jeffrey, K.R., Komor, E., Callaghan, P.T., 1997. A non-invasive measurement of phloem and xylem water flow in castor bean seedlings by nuclear magnetic resonance microimaging. Planta, 201, 53-63 Scopus.

Lancashire, J.R., Ennos, A.R., 2002. Modelling the hydrodynamic resistance of bordered pits. J. Exp. Bot., 53, 1485-1493 Scopus.

Lang, A., 1978. A model of Mass Flow in the Phloem. Aust. J. Plant Physiol., 5, 535546.

Lang, A., 1979. A relay mechanism for phloem translocation. Annals of Botany, 44, 141-145 Scopus.

Lang, A., 1983. Turgor-regulated translocation. Plant Cell Environ., 6, 683-689.

McCulloh, K.A., Sperry, J.S., Adler, F.R., 2003. Water transport in plants obeys Murray's law. Nature, 421, 939-942 Scopus.

McQueen, J.C., Minchin, P.E.H., Thorpe, M.R., Silvester, W.B., 2005. Short-term storage of carbohydrate in stem tissue of apple (Malus domestica), a woody perennial: evidence for involvement of the apoplast. Functional plant biology, 32, $1027-1031$ Scopus.

Mencuccini, M., 2003. The ecological significance of long distance water transport: short-term regulation and long-term acclimation across plant growth forms. Plant Cell Environ., 26:163-182 Scopus.

Mencuccini, M., Hölttä, T., Petit, G., Magnani, F., 2007. Sanio's Laws revisited. Sizedependent changes in the xylem architecture of trees. Ecology Letters, 10, 10841093 Scopus. 
Minchin, P.E.H., Thorpe, M.R., 1987. Measurement of unloading and reloading of photo-assimilate within the stem of bean. J. Exp. Bot., 38, 211-220.

Minchin, P.E.H., Lacointe, A., 2004. New understanding on phloem physiology and possible consequences for modelling long-distance carbon transport. New Phytologist, 166, 771-779 Scopus.

Minchin, P.E.H, 2007. Mechanistic modelling of carbon partitioning. In J. Vos, L.F.M. Marcelis, P.H.B. de Visser, P.C. Struik and J.B. Evers (eds.), FunctionalStructural Plant Modelling in Crop Production, 113-122. Springer.

Morison, K.R., 2002. Viscosity equations for sucrose solutions: old and new 2002. In: Proceedings of the 9th APCChE Congress and CHEMECA 2002, Paper \# 984.

Peel, A.J., Weatherly, P.E., 1962. Studies in sieve-tube exudation through aphid mouth-parts: the effect of light and girdling. Annals of Botany, 26, 633-646.

Peuke, A.D., Rokitta, M., Zimmermann, U., Schreiber, L., Haase, A. 2001. Simultaneous measurement of water flow velocity and solute transport in xylem and phloem of adult plants of Ricinus communis over a daily time course by nuclear magnetic resonance spectrometry. Plant Cell Environ., 24, 491-503 $\underline{\text { Scopus. }}$

Perämäki M., Vesala, T., Nikinmaa, E., 2005. Modeling the dynamics of pressure propagation and diameter variation in tree sapwood. Tree Physiology, 25, 10911099 Scopus.

Phillips, R.J., Dungan, S.R., 1993. Asymptotic analysis of flow in sieve tubes with semi-permeable walls. J. Theor. Biol. 162, 465-485 Scopus.

Salleo S., Lo Gullo M., Trifilò P. \& Nardini A (2004) New evidence for a role of vessel-associated cells and phloem in the rapid xylem refilling of cavitated stems of Laurus nobilis. Plant Cell Environ. 27, 1065-1076 Scopus.

Salleo, S., Trifilò, P., Lo Gullo, M.A. 2006. Phloem as a possible major determinant of rapid cavitation reversal in stems of Laurus nobilis (laurel). Functional Plant Biology, 33, 1063-1074 Scopus. 
Smith, K.C., Magnuson, C.E., Goeschl, J.D., DeMichele, D.W. 1980. A timedependent mathematical expression of the Münch hypothesis of phloem transport. J. Theor. Biol., 86, 493-505 $\underline{\text { Scopus. }}$

Smith, J.A.C, Milburn, J.A. 1980. Osmoregulation and the Control of Phloem-Sap Composition in Ricinus communis L. Planta, 148, 28-34 Scopus.

Taiz, L., Zeiger, E. 1998. Plant Physiology, Ed 2, Sineaur, Massachusetts.

Thompson M.V. (2005) Scaling phloem transport: Elasticity and pressureconcentration waves. J. Theor. Biol. 236, 229-41 $\underline{\text { Scopus. }}$.

Thompson M.V. (2006) Phloem: the long and the short of it. Trends in Plant Science $11,26-32 \underline{\text { Scopus }}$

Thompson, M.V., Holbrook, N.M., 2003a. Application of a single-solute non-steadystate phloem model to the study of long-distance assimilate transport. J. Theor. Biol., 220, 419-455 $\underline{\text { Scopus. }}$.

Thompson, M.V., Holbrook N.M, 2003b. Scaling phloem transport: water potential equilibrium and osmoregulatory flow. Plant Cell Environ., 26, 1561-1577 Scopus

Thompson, M.V., Holbrook, N.M., 2004. Scaling phloem transport: information transmission. Plant Cell Environ., 27, 509-519 Scopus.

Thompson, M.V., Zwieniecki, M.A., 2005. The role of potassium in long distance transport in plants. In: Holbrook, N.M., M.A., Zwieniecki, Vascular Transport in plants, Elsevier Academic Press.

Thorpe, M.R., Minchin, P.E.H., 1996. Mechanisms of long and short distance transport from sources to sinks. In: Zamski, E. and Schaffer, A.A. eds. Photoassimilate distribution in plants and crops: source-sink relationships. Dekker, New York, 261-282. 
Tyree, M.T., Sperry, J.S., 1988. Do woody plants operate near the point of catastrophic xylem dysfunction caused by dynamic water stress? Plant Physiol., $88,574-580$

Tyree, M., 2003. Plant hydraulics: The ascent of water. Nature, 423, 923 Scopus.

Tyree, M.T., Zimmermann, M.H., 2002. Xylem Structure and the Ascent of Sap. Springer, Berlin.

Van Bel, A.J.E., 1990. Xylem-Phloem Exchange Via the Rays: The Undervalued Route of Transport. J. Exp. Bot., 41,631-644

Vaughn, M.W., Harrington, G.N., Bush D.R., 2002. Sucrose-mediated transcriptional regulation of sucrose symporter activity in the phloem. PNAS, 99, 10876-10880 Scopus.

Vreugdenhil, D., 1985. Source-to-sink gradient of potassium in the phloem. Planta, $211,105-11$ Scopus.

West, G.B., Brown, J.H., Enquist, B.J., 1999. A general model for the structure and allometry of plant vascular systems. Nature, 400, 664-667 Scopus.

Wheeler, J.K., Sperry, J.S., Hacke, U.G., Hoang, N., 2005. Inter-vessel pitting and cavitation in woody Rosaceae and other vesselled plants: a basis for a safety versus efficiency trade-off in xylem transport. Plant Cell Environ., 28, 800-812 $\underline{\text { Scopus. }}$

Windt, C.W., Vergeldt, F.J., De Jager P.A., Van As, H, 2006. MRI of long-distance water transport: a comparison of the phloem and xylem flow characteristics and dynamics in poplar, castor bean, tomato and tobacco. Plant Cell Environ., 29, 1715-1729 $\underline{\text { Scopus. }}$

Woodruff, D.R., Bond, B.J., Meinzer, F.C., 2004. Does turgor limit growth in tall trees? Plant Cell Environ., 27, 229-236 Scopus. 
Zwieniecki, M.A., Melcher, P.J., Holbrook, N.M., 2001. Hydraulic properties of individual xylem vessels of Fraxinus americana. J. Exp. Bot., 52, 257-264 Scopus.

Zwieniecki M.A., Melcher P.J. \& Holbrook N.M. (2001) Hydrogel Control of Xylem Hydraulic Resistance in Plants. Science, 291, 1059 - 1062 Scopus. 
Fig 1A) Sum of the radial water fluxes between xylem and phloem as a function of the sugar concentration at the sugar loading zone. Negative values mean that the flux is towards the xylem, positive values towards the phloem. Where the horizontal zero line crosses one of the curves, the intersection points indicate achievement of steady state transport conditions, with no net water flux towards either xylem or phloem. When the number of tubes is progressively reduced, the two intersection points gradually move towards each other until only one solution is found. With further decreases in the number of tubes, no steady-state solution is found any longer.

Fig 1B) Vertical distribution of phloem turgor and osmotic pressure as a function of distance from the source, for the case with minimum number of tubes and for the case where there is twice the number of tubes.

Fig.2) The minimum number of xylem and phloem tubes in relation to the base case presented in fig. 1 required for transport as a function of the daily minimum xylem water potential. Xylem tube number is shown in relation to the xylem tube number at - 2.0 MPa and phloem tube number is shown in relation to the phloem tube number at $-2.0 \mathrm{MPa}$

Fig. 3A) Phloem turgor, osmotic pressure and water potential profiles with the case of one relay.

Fig 3B) Phloem turgor, osmotic pressure and water potential profiles with the case of four relays. 
Fig 3C) Radial and axial water fluxes for the case of two relays.

Fig. 3D) Changes in the minimum number of required phloem tubes as a function of the number of relays. Numbers of required phloem tubes are expressed relative to the required number when no relays are present.

Fig. 4A) Changes in the pressure difference between the two ends of the tube and parameter $F$ as a function of the number of sieve tubes for varying sugar concentrations at the sugar sink. The number of tubes is shown in relation to the minimum needed for mass translocation.

Fig 4B) Changes in solution transit time and wave propagation time as a function of number of tubes for varying sugar concentrations at the sugar sink. The number of tubes is shown in relation to the minimum needed for mass translocation.

Fig 5. Changes in the number of phloem tubes, transit time, wave propagation time and $F$ as a function of diameter in the bottom element (equivalent to sieve tube tapering). All parameters were relativised to allow plotting on a common axis. Tube diameters at the top element were set at $10 \mu \mathrm{m}$, whereas diameters at the bottom element were progressively increased using a linear tapering function.

Fig. 6. The minimum number of xylem and phloem tubes in relation to the base case presented in fig. 1 required for transport as a function of phloem potassium loading rate. The resulting osmotic concentration due to potassium at sugar source is shown also. 


\section{Appendix A. Method of solving the phloem flow equations.}

Sugar concentration was given an initial value at the topmost sieve tube element. Phloem turgor pressure, sugar concentration, axial and radial water fluxes were then calculated for each element following the procedure described below.

Sugar source element $(i=N)$ :

-Viscosity was calculated from concentration using Eq. (12).

-Axial sap flow from the top element (i.e., downstream) was calculated using sugar conservation Eqn. (10) (and the relation $J_{s, i}=J_{i}^{a} c_{i}$ ) to be the sugar loading rate divided by concentration

$J_{N}^{a}=\frac{S_{N}}{C_{N}}$

-Radial water flow from the xylem was equated to the axial flow according to Eq. (9)

$$
J_{N}^{r}=J_{N}^{a}
$$


-Turgor pressure was now solved from Eq. (7). The viscous pressure loss in the element due to the sap flow was deducted from the turgor pressure according to Eqn. (8). The gravitational term was also taken into account.

$$
P_{p, N}=\frac{J_{N}^{r}}{k_{r}}+P_{x, N}+c_{N} R T-\frac{J_{N}^{a}}{k_{p, N}^{a}}+\rho g l_{N}
$$

\section{Path elements $(1<\mathbf{i}<\mathbf{N})$ :}

The following procedure was repeated iteratively for the element until concentration did not change anymore. This was done because an approximate value for viscosity was used in the first step before concentration was calculated.

-Turgor pressure was calculated from Eqn. (8)

$P_{p, i}=P_{p, i+1}-\frac{J_{p, i+1}^{a}}{k_{p, i}^{a}}+\rho g l_{i}$

-Concentration was solved from equations (7), (9) and (10). Combining equations (7), (9) and (10) results in a quadratic equation, which was solved.

$K_{1} c_{i}^{2}+K_{2} c_{i}+K_{3}=0$ 
where

$K_{1}=k^{r} R T$

$K_{2}=J_{i+1}^{a}+\left(P_{x, i}-P_{p, i}\right) k^{r} A_{r}$

$K_{3}=-J_{i+1}^{a} c_{i+1}$

-Radial flow was solved from Eqn. (7)

$J_{i}^{r}=k^{r}\left(P_{x, i}-P_{p, i}+c_{i} R T\right)$

-Axial flow was solved from the sugar conservation Eqn. (10) (and the relation $\left.J_{s, i}=J_{i}^{a} c_{i}\right)$

$J_{i}^{a}=J_{i+1}^{a} \frac{c_{i+1}}{c_{i}}$

-Viscosity was calculated from concentration (Eqn. (12))

Sugar sink element $(i=1)$ :

-Concentration was solved from eq. (11). 
$c_{1}=\frac{J_{2}^{a} c_{2}}{A_{1}}+\frac{-P_{x, 1}+P_{a}}{R T}$

-Viscosity was calculated from Eqn. (12).

-Turgor pressure was solved from Eqn. (8).

$P_{p, 1}=P_{p, 2}-\frac{J_{2}^{a}}{k_{p, 1}^{a}}+\rho g l_{1}$

-Radial water flux was solved from (7).

$J_{1}^{r}=k^{r}\left(P_{x, 1}-P_{p, 1}+c_{1} R T\right)$

Radial water fluxes from all the elements were summed. If the sum was zero (actually absolute value smaller than a required precision) then this was a steady state solution. If the sum was non-zero (actually the absolute value larger than a required precision), the sugar concentration at the topmost element was varied and the procedure described above was repeated. This was continued until the sum of the radial water fluxes over all the elements was smaller than the required precision. The required precision was set to be such that the absolute value of the sum of water fluxes was less than one thousandth of the sum of the absolute water fluxes. This is the same criteria and precision as used by Goeschl et al. (1976). 


\section{Table 1. Parameter values}

\begin{tabular}{|l|l|}
\hline Tree leaf area & $50 \mathrm{~m}^{2}$ \\
\hline Radius of xylem conduit and & $10 \mu \mathrm{m}$ \\
phloem sieve tubes & \\
\hline Daile per tree & $0.9 \mathrm{~g} \mathrm{~s}^{-1}$ \\
\hline Daily maximum & \\
photosynthetic rate per tree & $30.0 \mu \mathrm{mol} \mathrm{s}^{-1}$ \\
\hline Sugar loading rate & $15.0 \mu \mathrm{mol} \mathrm{s}^{-1}$ \\
\hline Xylem water potential at the & $-2 \mathrm{MPa}^{-1}$ \\
\hline leaves (sugar source) & $10 \mathrm{~m}^{-1}$ \\
\hline Soil water potential & $0 \mathrm{MPa}^{-13} \mathrm{~m} \mathrm{~Pa}^{-1} \mathrm{~s}^{-1}$ \\
\hline Radial hydraulic conductance & $2 * 10^{-13}$ \\
between xylem and phloem & \\
\hline Plant height & \\
\hline Unloading coefficient $\mathrm{A}_{1}$ & \\
\hline
\end{tabular}


Fig 1.

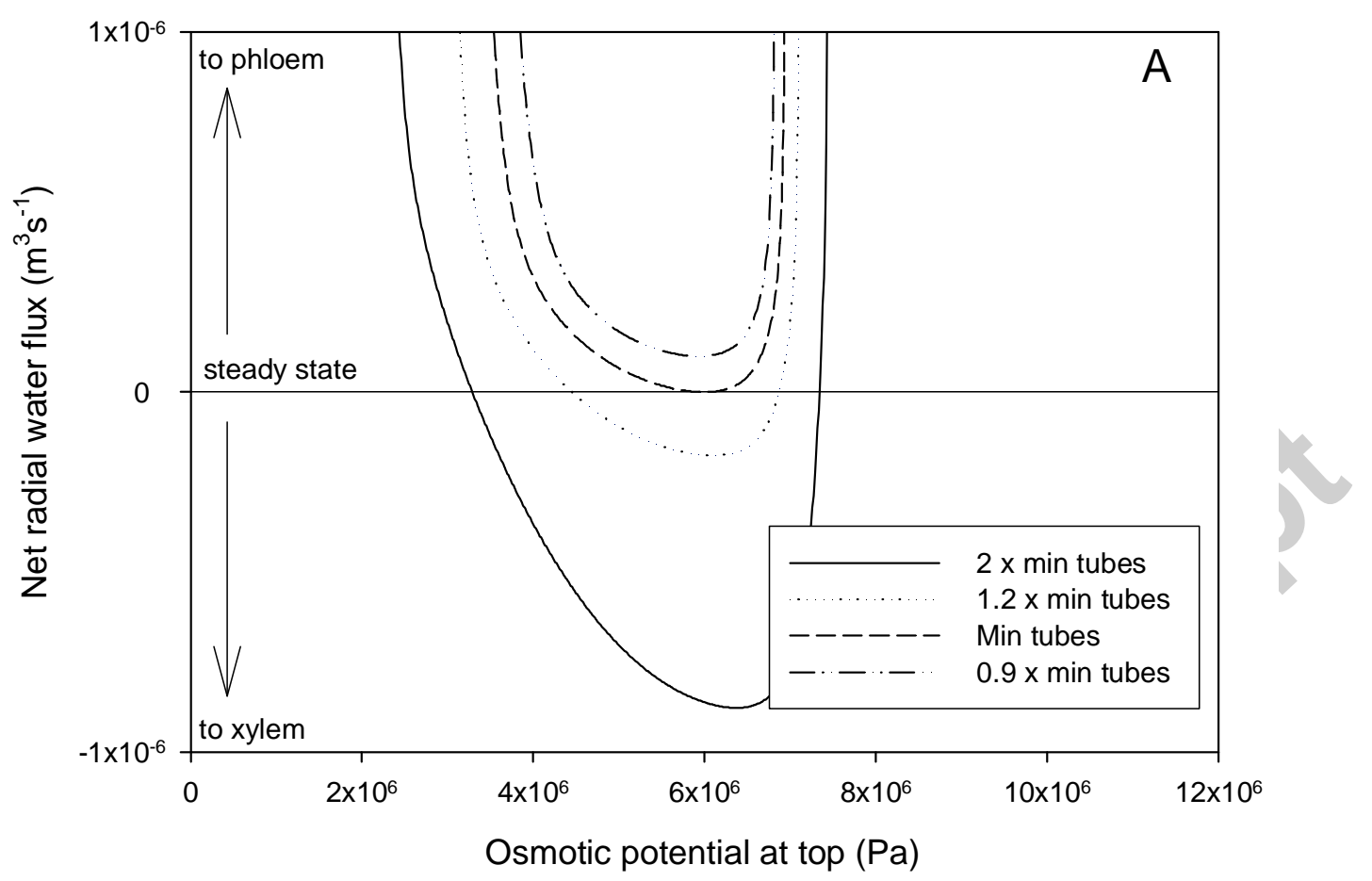




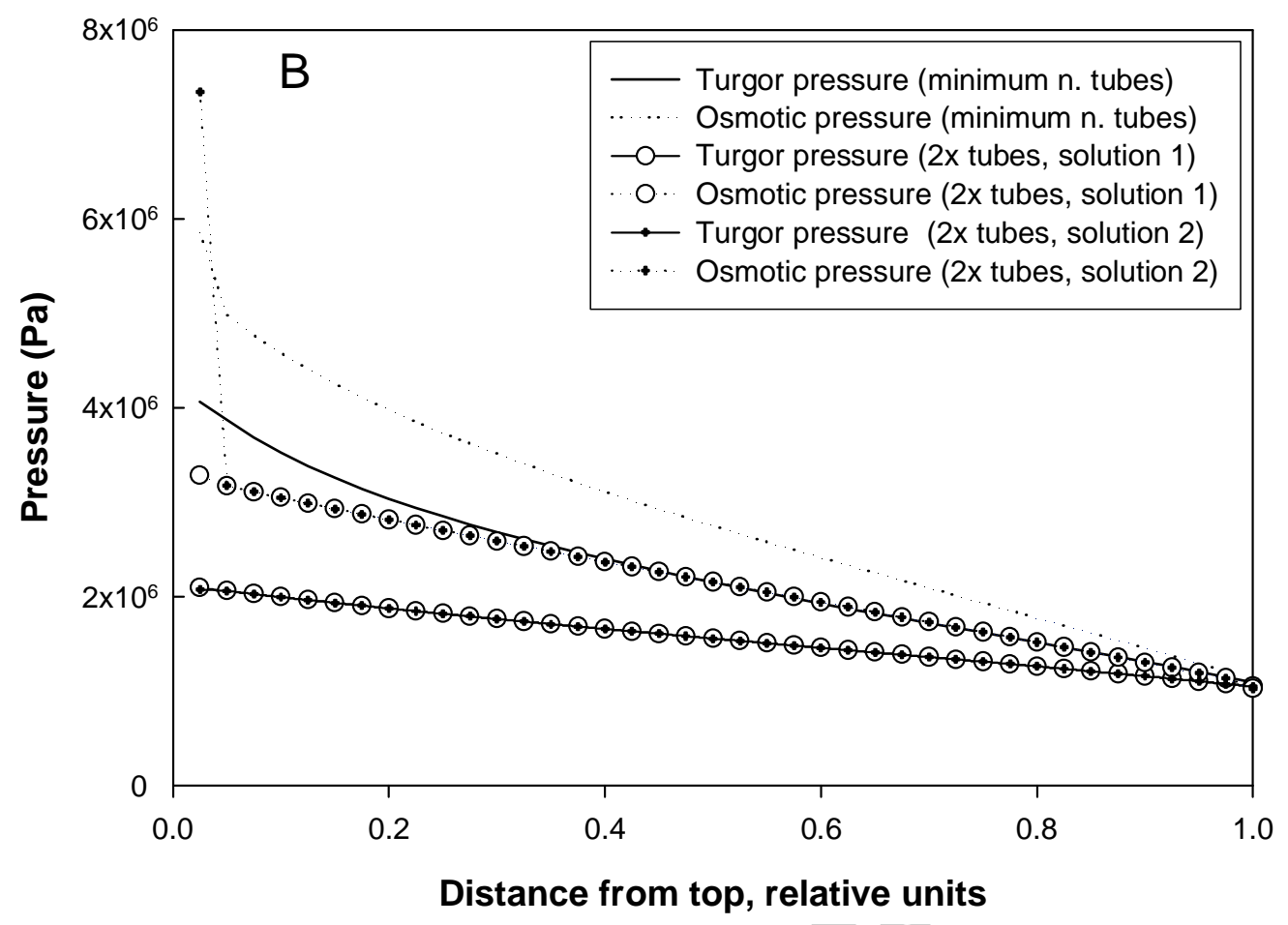


Fig 2.

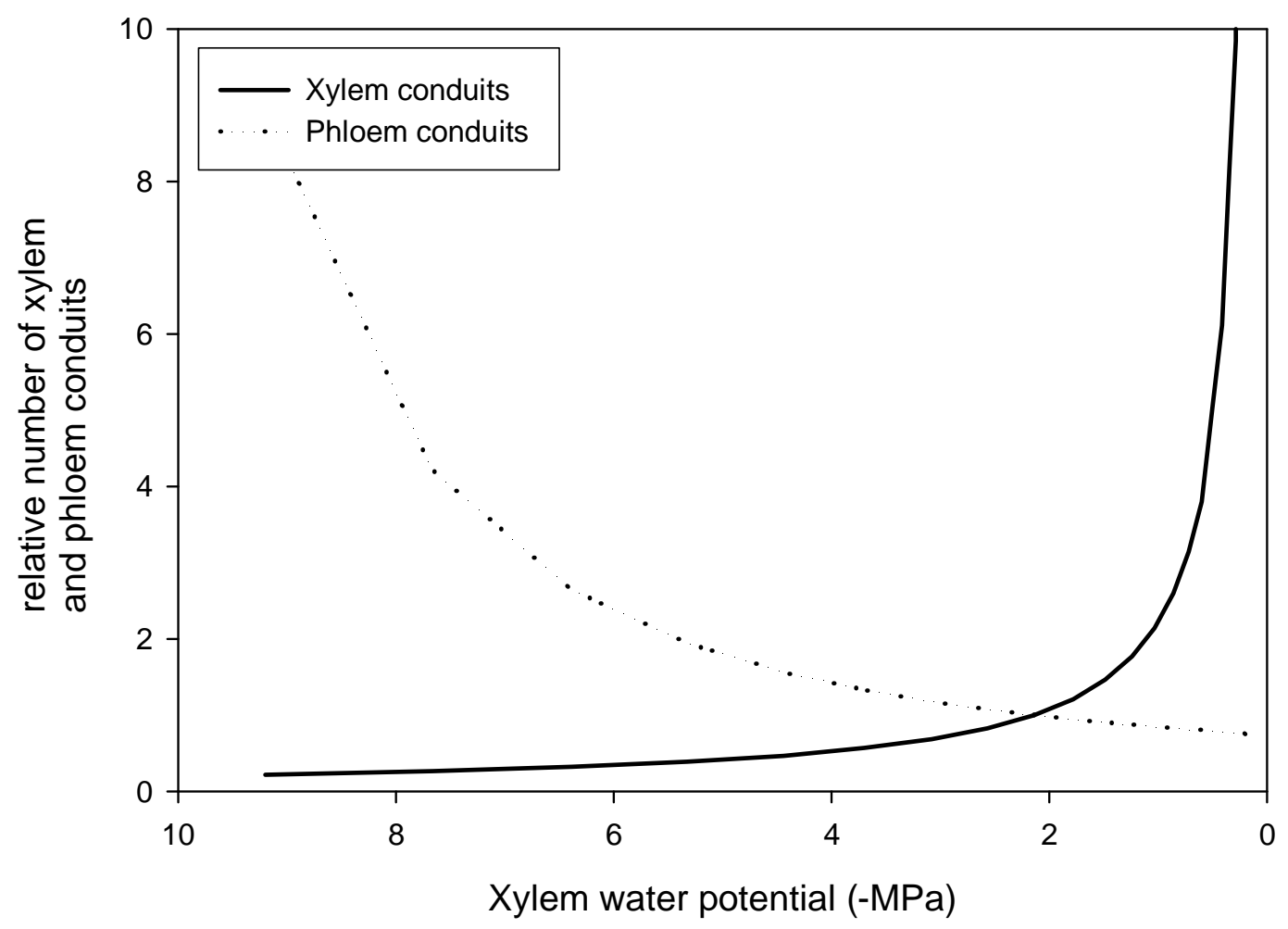


Fig 3.

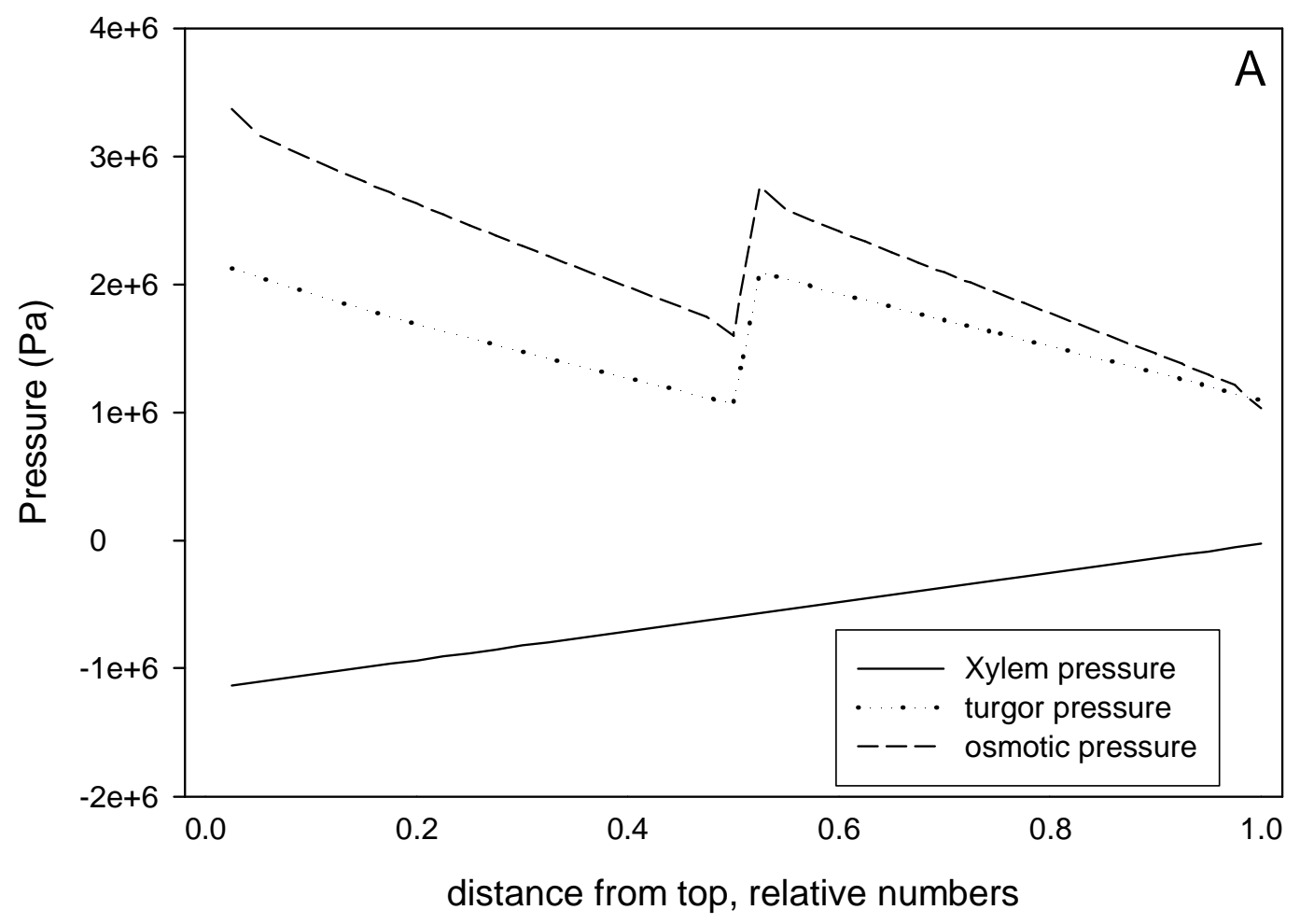



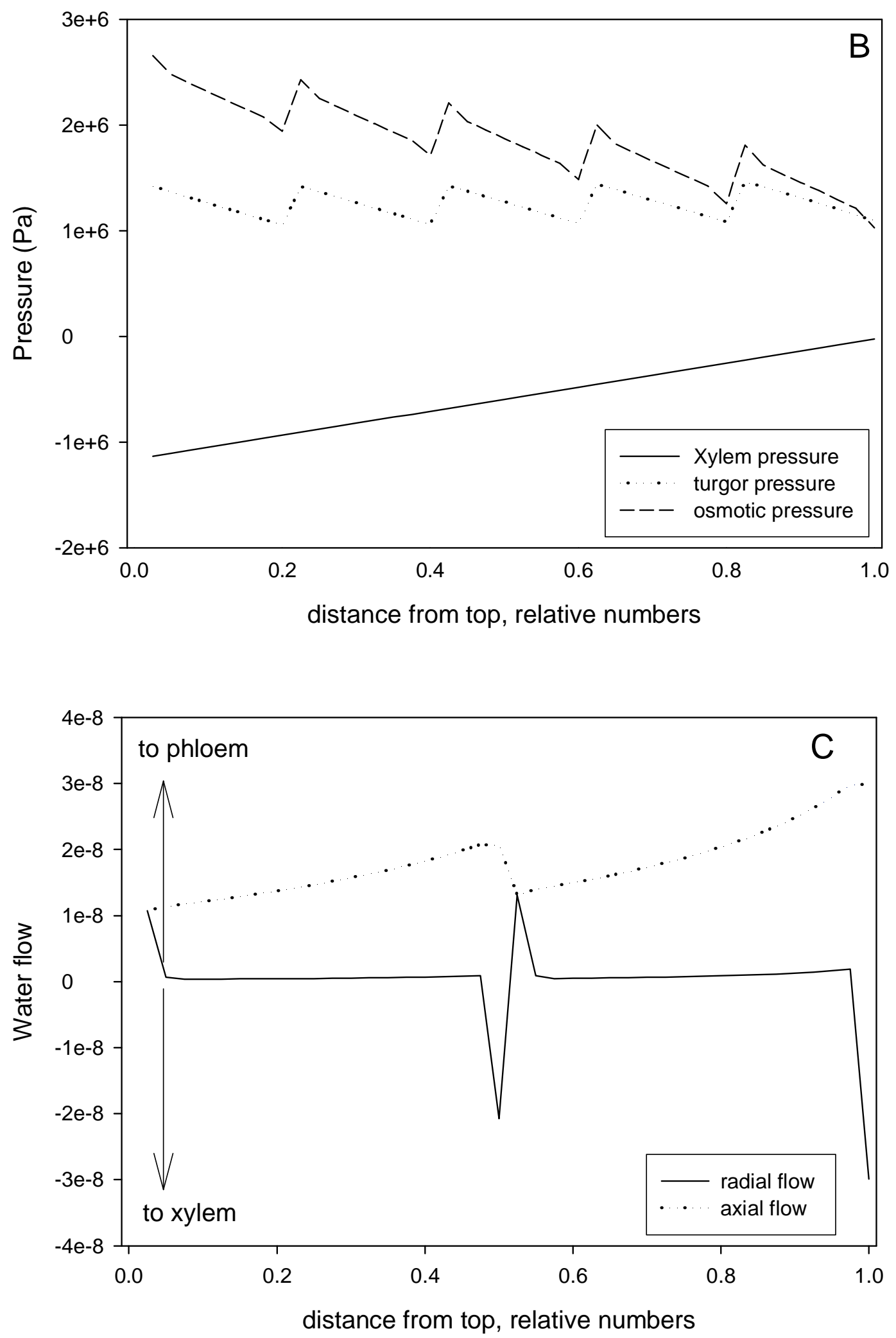


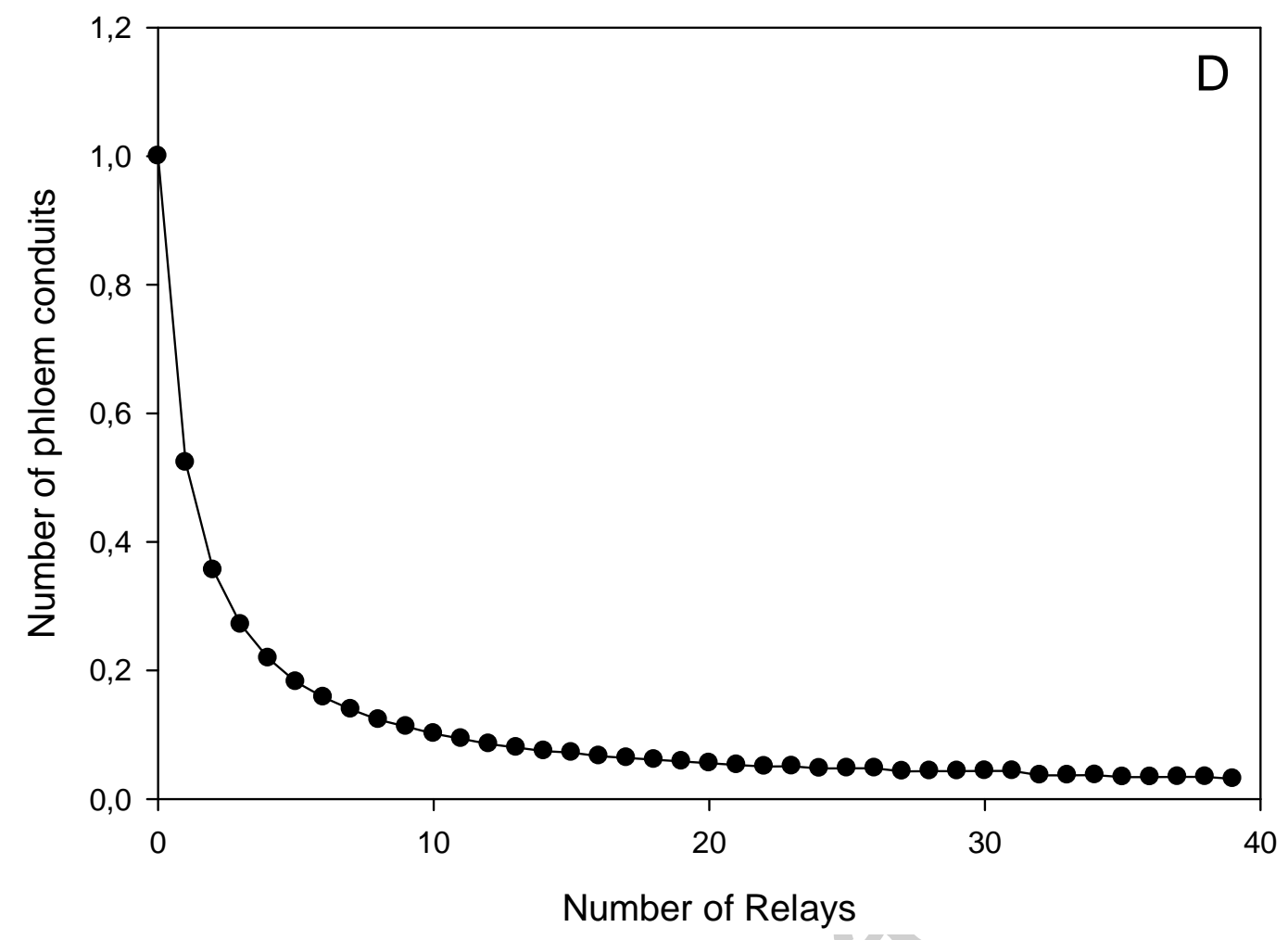


Fig 4.

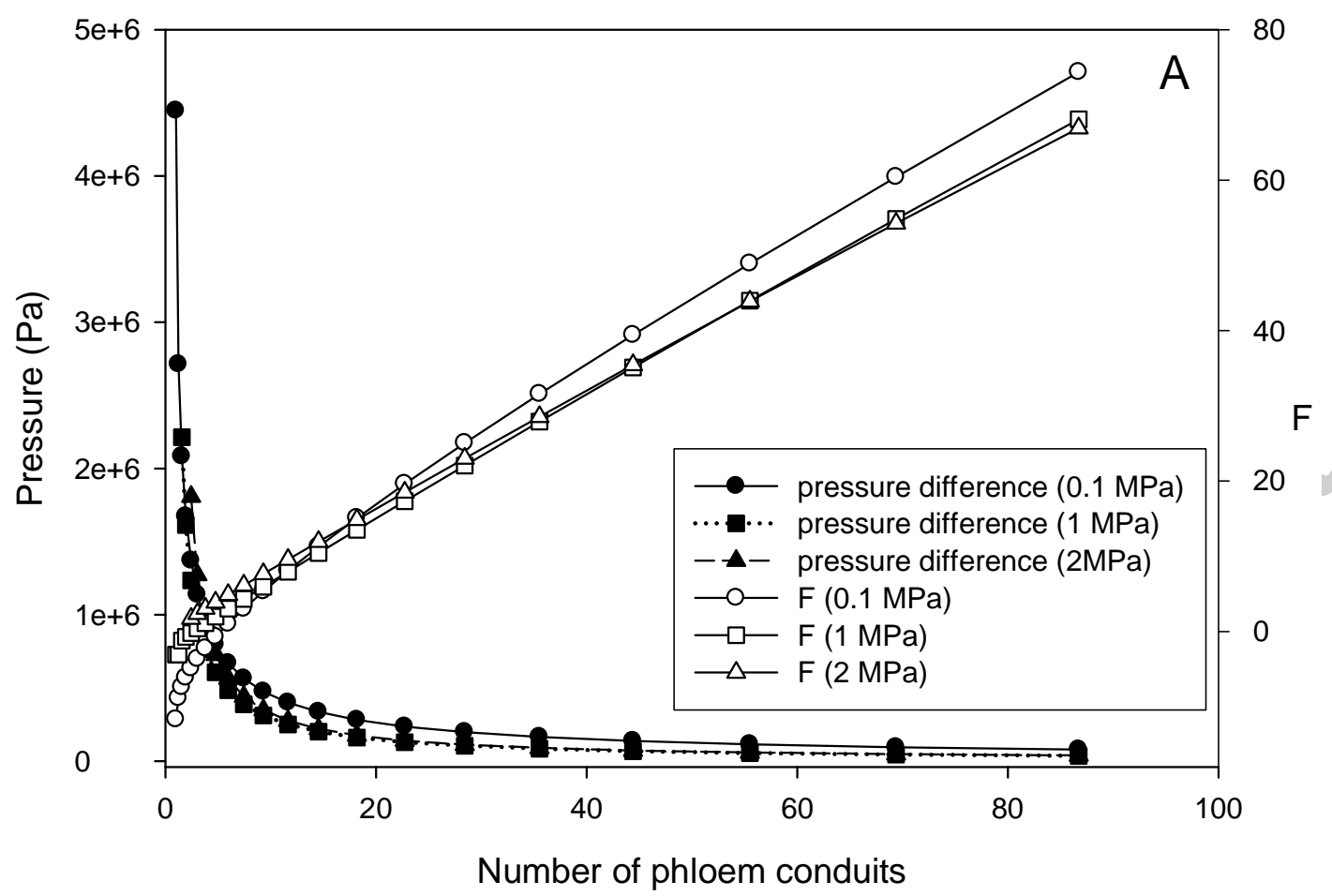




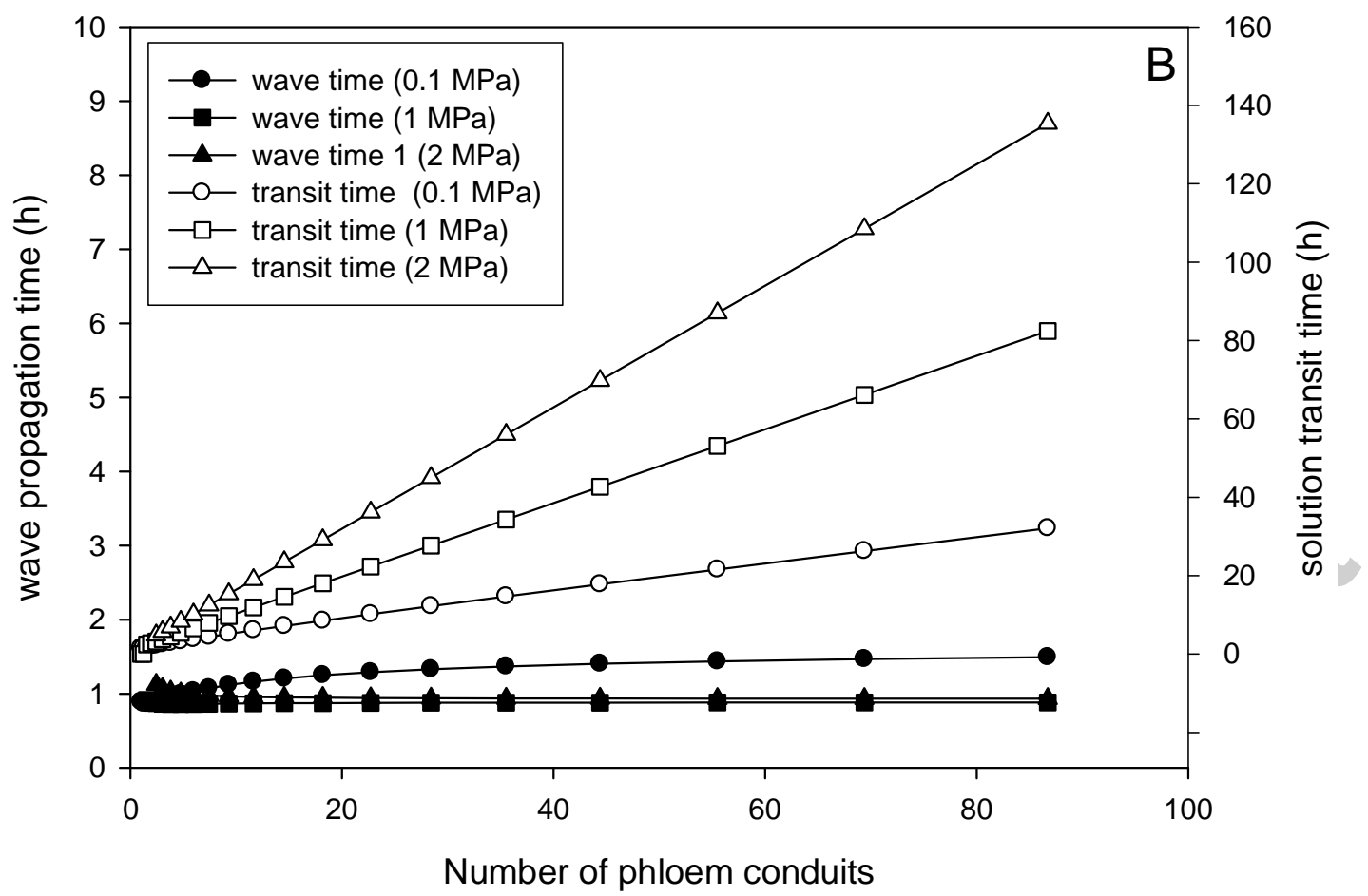


Fig 5.

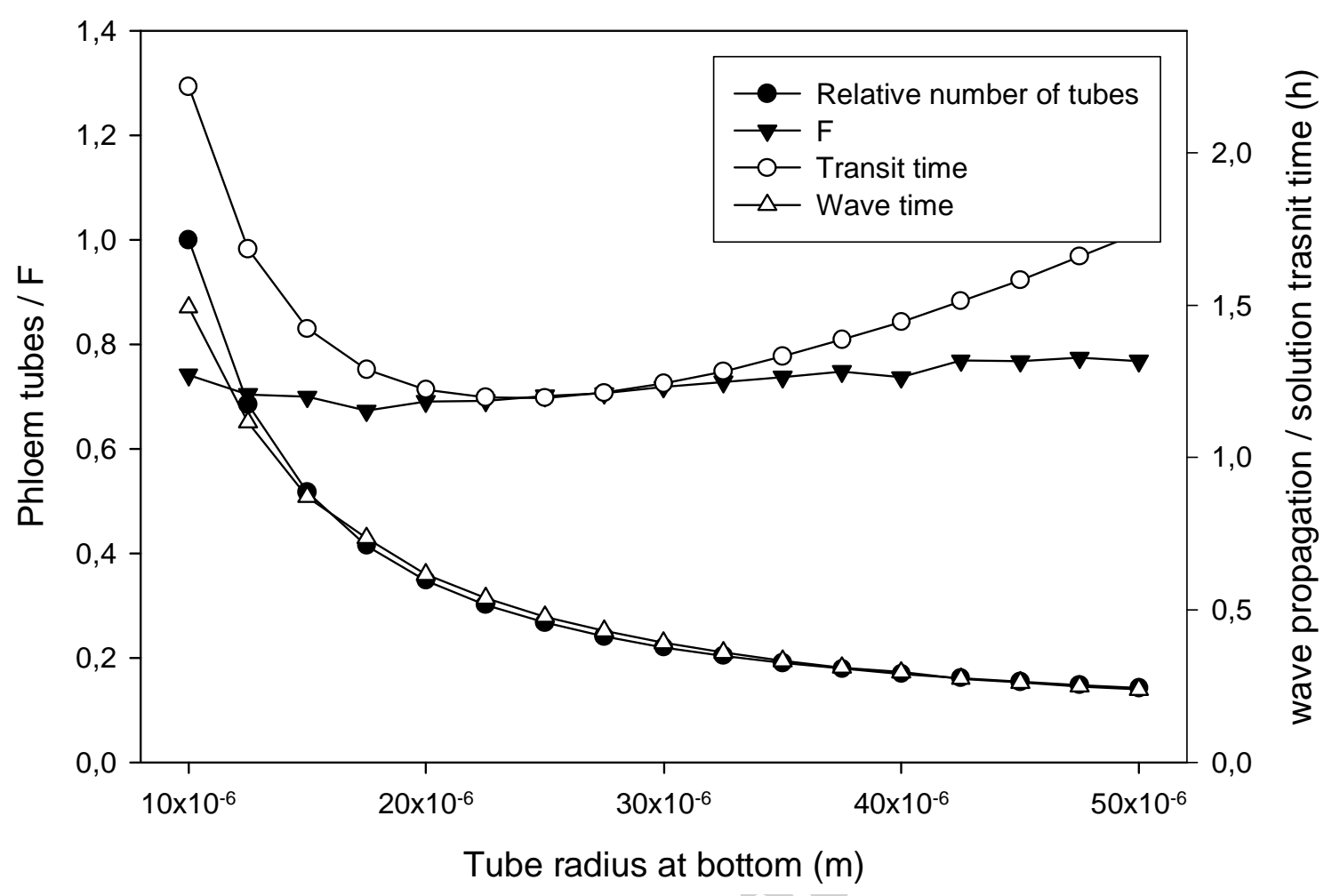


Fig 6.

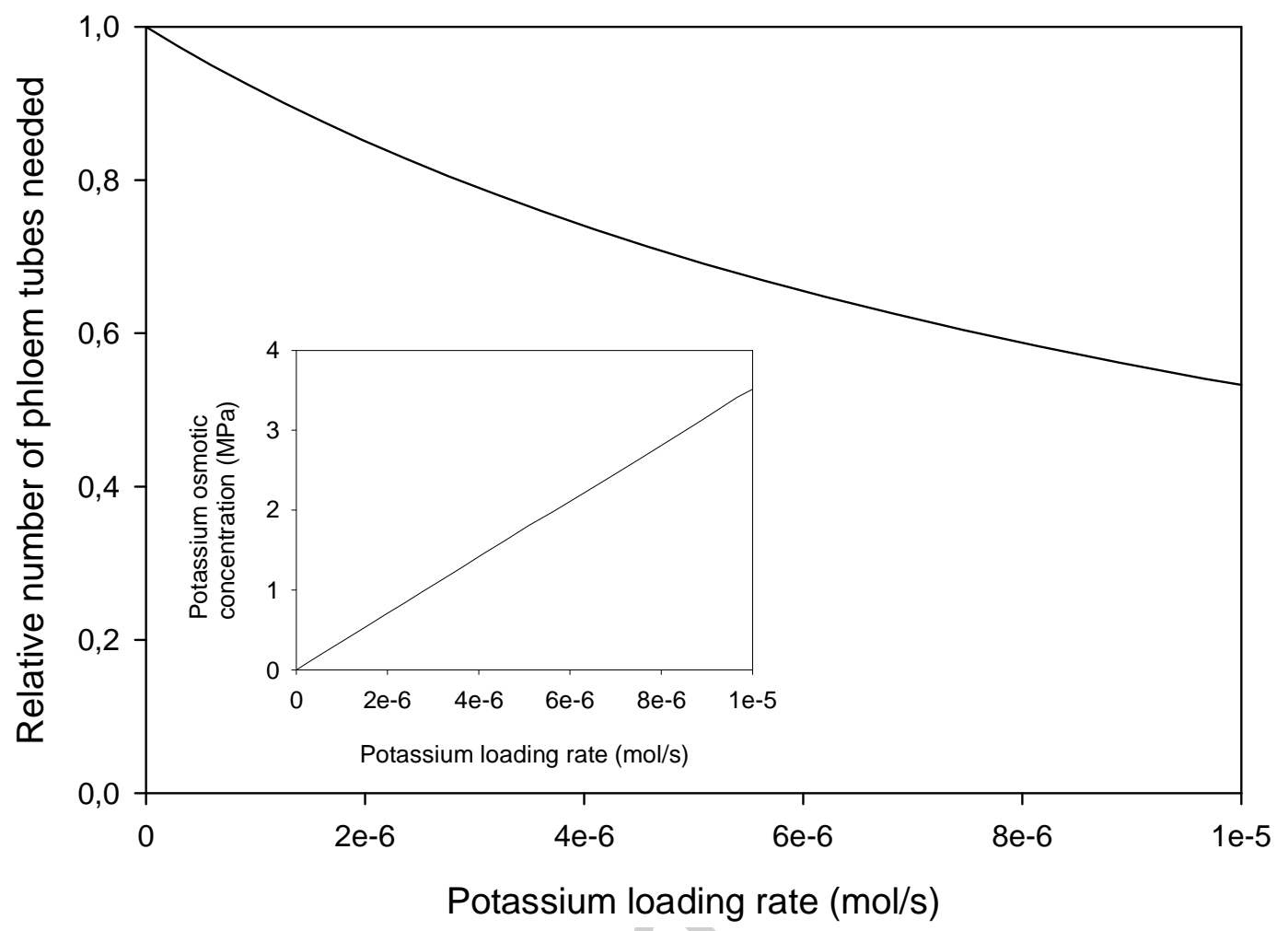

